\title{
The application prospect of metal/metal oxide nanoparticles in the treatment of osteoarthritis
}

\author{
Junchao Luo ${ }^{1,2} \cdot$ Yin Zhang ${ }^{1,3} \cdot$ Senbo Zhu ${ }^{1,2} \cdot$ Yu Tong $^{1,2} \cdot$ Lichen $\mathrm{Ji}^{1,2} \cdot$ Wei Zhang ${ }^{1,4} \cdot$ Qiong Zhang $^{5} \cdot$ Qing Bi ${ }^{1,2}$
}

Received: 5 April 2021 / Accepted: 28 July 2021 / Published online: 20 August 2021

(c) The Author(s) 2021

\begin{abstract}
The current understanding of osteoarthritis is developing from a mechanical disease caused by cartilage wear to a complex biological response involving inflammation, oxidative stress and other aspects. Nanoparticles are widely used in drug delivery due to its good stability in vivo and cell uptake efficiency. In addition to the above advantages, metal/metal oxide NPs, such as cerium oxide and manganese dioxide, can also simulate the activity of antioxidant enzymes and catalyze the degradation of superoxide anions and hydrogen peroxide. Degrading of metal/metal oxide nanoparticles releases metal ions, which may slow down the progression of osteoarthritis by inhibiting inflammation, promoting cartilage repair and inhibiting cartilage ossification. In present review, we focused on recent research works concerning osteoarthritis treating with metal/metal oxide nanoparticles, and introduced some potential nanoparticles that may have therapeutic effects.
\end{abstract}

Keywords Metal nanoparticles $\cdot$ Metal oxide nanoparticles $\cdot$ Osteoarthritis $\cdot$ Cartilage $\cdot$ Oxidative stress

\section{Introduction}

Osteoarthritis, the most common chronic joint disease, involves the molecular, biochemical, morphological, biomechanical changes of all components in joint. It is characterized by progressive degeneration of articular cartilage and abnormal bone remodeling (Hunter and Bierma-Zeinstra 2019). Gender, obesity, genetic predisposition, mechanical load and other factors involve in the occurrence of osteoarthritis, among which aging is the most important factor (Abramoff and Caldera 2020). Systemic inflammation is an important feature of aging. Inflammatory cytokines caused chondrocytes and synoviocytes to secrete matrix

Qing Bi

biqing@hmc.edu.cn; bqzjsrmyy@163.com

1 Department of Orthopedics, Zhejiang Provincial People's Hospital, Hangzhou 310014, Zhejiang, China

2 Department of Orthopedics, The Second Affiliated Hospital of Wenzhou Medical University, Xueyuan Xi Road 109\#, Wenzhou 325027, Zhejiang, China

3 Bengbu Medical College, Bengbu 233030, Anhui, China

4 Qingdao University, Qingdao 266071, Shandong, China

5 Operating Theater, Zhejiang Provincial People's Hospital, Hangzhou 310014, Zhejiang, China metalloproteinases (MMPs) and a disintegrin and metalloproteinase with thrombospondin motifs (ADAMTs), which promoted cartilage matrix degradation. Mechanical overloading can directly promote the secretion of inflammatory cytokines by chondrocytes, and indirectly cause synovial inflammation through the generation of cartilage fragments, leading to the increase of inflammatory cytokines in synovial fluid (Scanzello and Goldring 2012). The redox state also has a significant effect on the function of chondrocytes. Reactive oxygen species (ROS) and reactive nitrogen species (RON) refer to reactive free radicals and non-free radical derivatives of oxygen and nitrogen respectively, which are the main factors affecting the redox homeostasis in cells (Liguori et al. 2018). During cellular senescence, the activity of antioxidant enzymes such as superoxide dismutase (SOD) and glutathione peroxidase (GSH) decreases, while systemic inflammation and mitochondrial dysfunction as hallmark of senescence lead to increased production of ROS/RON (Watanabe et al. 2014; Martínez et al. 2020, Coryell et al., 2021). The imbalance between the production of ROS/RON and the scavenging action of the antioxidant system results in oxidative stress. Oxidative stress causes DNA damage, protein peroxidation and lipid peroxidation. Mitochondrial DNA damage in turn aggravates mitochondrial dysfunction (Coryell et al. 2021). ROS/RON activate NF- $\mathrm{KB}$ pathway by modifying IкB kinase and promote the production of 
inflammatory cytokines (Lepetsos et al. 2019). In addition, lipid peroxides, such as ox-LDL, also promote systemic inflammation (Rhoads and Major 2018). ROS/RON inhibits cartilage matrix synthesis by regulating PI3K/Akt and MAPK pathways, and promotes cartilage matrix degradation directly or indirectly by promoting the expression of MMPs (Bai et al. 2019).

Metal/metal oxide nanoparticles (NPs) ( 100 nm) have unique physical properties compared to microparticles $(500 \mathrm{~nm} \sim)$. NPs have a large surface area to volume ratio, which confers them high surface reactivity. On the one hand, it allows them to simulate the activity of multiple antioxidant enzymes such as SOD and catalase (CAT). In general, the smaller the particle size, the stronger the catalytic activity. On the other hand, it allows them to attach easily to cell membranes, thus increasing cell uptake (Bai et al. 2019). After entering cells, metal/metal oxide NPs exert anti-oxidative stress and anti-inflammatory effects by regulating redox state and releasing metal ions (Agarwal et al. 2019). However, high surface reactivity is also a double-edged sword. Increased cell uptake efficiency increases both bioavailability and toxicity (Mangalampalli et al., 2018, Ashrafi et al. 2019). Metal/metal oxide NPs can promote the production of ROS through mitochondrial and NADPH oxidase perturbation (Sun et al. 2018; Mukherjee and Acharya 2018). Accumulation of heavy metal ions in chondrocytes and osteoblasts causes cellular dysfunction by replacing essential elements in enzymes and disrupting the conformation of active sites, thus increasing the risk of osteoarthritis and osteoporosis (Bolduc et al., 2019, Wang et al. 2016).

Fortunately, metal/metal oxide NPs have shown strong anti-oxidative stress and the ability to promote cartilage repair at lower concentrations. This article introduces the protective metal elements for articular cartilage and the potential metal/metal oxide NPs in the treatment of osteoarthritis.

\section{Cellular internalization and cartilage penetration of nanoparticles}

\section{Cellular internalization}

Unlike metal ions that enter the cell via ion channels, the main way metal/metal oxide nanoparticles enter the cell is endocytosis, including clathrin-mediated endocytosis, caveolae-mediated endocytosis, lipid raft-mediated endocytosis and clathrin/caveolae/lipid-independent endocytosis (Bajpayee et al. 2015) . NPs sizes of around $2 \mathrm{~nm}$ require less energy to overcome the water barrier between the particle and the cell membrane, while it is easily to be retained in the hydrophobic core of the phospholipid bilayer. With the increase of particle size, the ability of NPs to escape capture is enhanced, but the energy barrier to overcome when passing through the water barrier is also significantly increased (Burgess et al. 2020). In the study of Jiang et al., gold NPs with particle size of $2-6 \mathrm{~nm}$ can enter cells by direct diffusion, and with the increase of particle size, the proportion of NPs entering cells by direct diffusion gradually decreases (Jiang et al. 2015). For most metal/metal oxide NPs larger than $8 \mathrm{~nm}$, it is difficult for them to penetrate directly through the phospholipid bilayer or through micropores in the cell membrane to enter the cell. Metal/metal oxide NPs adhere to cell membranes through electrostatic interactions, van der Waals forces and spatial interactions. The cell membrane can be divided into a liquid ordered phase rich in lipids (lipid rafts) including cholesterol and phospholipids and a surrounding liquid-crystalline disordered phase. The adsorption of metal/metal oxide NPs causes the bending of the cell membrane. Due to the difference in thickness at the boundaries of the two lipids, metal/metal oxide NPs only need to overcome a lower energy barrier to bend the cell membrane. Therefore, they are more likely to be adsorbed at the boundaries (Ridolfi et al. 2020). Eventually, the membrane invaginates to form a vesicle that completes endocytosis. In macrophages and neutrophils, phagocytosis is also involved in the uptake of metal/metal oxide NPs.

The internalization of metal/metal oxide NPs by cells is mainly affected by the following three aspects: (i) the type and state of cells; (ii) the physicochemical properties of NPs; (iii) biological and biochemical environments. There are differences in the uptake pathways of different cells (Wathiong et al. 2019). In addition, the state of the cell also plays an important role in the uptake of metal/metal oxide NPs. Recently, Farvadi et al. found that the uptake of gold NPs by normal fibrocells (HU02) cultured on a conventional twodimensional culture plate was significantly higher than that of cells cultured on a three-dimensional culture plate capable of mimics the in vivo cell morphology (Farvadi et al. 2018).

Among the physicochemical properties of NPs themselves, size and shape are important factors that affect the uptake of NPs. The clathrin-mediated endocytosis can form vesicles with a diameter of approximately $100-150 \mathrm{~nm}$ (less than $500 \mathrm{~nm}$ ), while the caveolae-mediated endocytosis can form vesicles with a diameter of approximately $60-80 \mathrm{~nm}$ (Murugan et al. 2015). Wu et al. compared the uptake efficiency of B16 cells for silver NPs with particle size ranging from 5 to $100 \mathrm{~nm}$, the results showed that $100 \mathrm{~nm}$ silver NPs had the highest uptake efficiency (Wu et al. 2019). Similarly, Ding et al. found that SMCC-7721, GES-1 and 4T1 cells had the highest uptake efficiency for gold NPs with a particle size of $80 \mathrm{~nm}$ within the range of $15 \mathrm{~nm}$ to $80 \mathrm{~nm}$ (Ding et al. 2018). Li et al. (2016) compared the uptake efficiency of human mesenchymal stem cells for spherical, star-shaped and rod-shaped gold NPs with size ranging from 40 to $110 \mathrm{~nm}$, the results showed that spherical NPs had 
the highest uptake efficiency (Ding et al. 2018). In terms of endocytosis kinetics, the internalization of NPs consists of two stages: invagination and wrapping. The largest local mean curvature of NPs with various shape is different, which makes the vary degree of membrane deformation during wrapping stage. Greater deformation usually means greater resistance (Li et al. 2012). Li et al. (2016) used DPD simulation method to study the effect of the elasticity of NPs on internalization in vitro. The results showed that the soft NPs deformed when they touched the lipid membrane. On the one hand, the deformation of NPs increases the largest local mean curvature, and on the other hand, allows the NPs to bind to a large number of mobile ligands during initial contact with the lipid membrane, resulting in a decrease in the number of mobile ligands on the lipid membrane covering the other side of the NPs, thereby limiting endocytosis (Li et al. 2015). However, the effect of elasticity on internalization of metal/metal oxide NPs with high density is negligible.

Surface potential and surface properties of NPs also play an important role in their internalization process. Because cell membranes usually carry negative charges, cationic NPs are more likely to attach to cells, while anionic NPs have ability to circulate steadily in the body. Surface modification of metal/metal oxide NPs can effectively reduce aggregation. The agglomeration of NPs increases the size and accelerates the deposition. In addition, the uptake of NPs can also be increased by binding specific or non-specific ligands on the surface of NPs (Li et al. 2015).

Biological and biochemical environments can influence the uptake of NPs too. After the metal/metal oxide NPs enter the biological fluid, they are quickly covered with organic materials, such as lipids and carbonic acid, thus forming a corona. Proteins play a main role in corona formation (Pareek et al. 2018). The factors affecting the formation of protein corona include particle size, shape, surface area to volume ratio and surface charge. On the one hand, protein corona influences the biological behavior of NPs. Protein corona can be recognized as ligands by receptors on the cell membrane, thus facilitating the uptake of NPs (BinnemarsPostma et al. 2016). Ding et al. compared the uptake of gold NPs by 7721 cells in serum and serum-free environments, the results showed that the uptake of silver NPs by 7721 cells in serum-free environments was changed to clathrin and caveolin-independent pathways (Ding et al. 2018). On the other hand, the NPs might also cause the proteins in the protein corona to unfold, thus causing biological toxicity.

\section{Cartilage penetration}

Articular cartilage is composed of chondrocytes and extracellular matrix. Glycosaminoglycans and proteoglycans fill a fibrous network of collagen and elastin to form the extracellular matrix. In terms of biomechanical behavior, articular cartilage consists of liquid phase composed mainly of water and solid phase represented by collagen and proteoglycan. The flow of the liquid phase in the solid phase provides the elasticity of the cartilage (Carballo et al. 2017). Repeated loading causes the decrease of tensile strength, stiffness and thickness of articular cartilage, leading to the occurrence of osteoarthritis (Vazquez et al. 2019). The fibrous network of collagen and elastin has a hydration spacing of approximately $0-100 \mathrm{~nm}$, while the gap between the glycosaminoglycan and proteoglycan side chains filled in them is about 0-15 nm (Krishnan and Grodzinsky 2018; Torzilli et al. 1997). The permeability of metal/metal oxide nanoparticles in cartilage mainly depends on particle size and surface potential. The metal/metal oxide NPs with particle size less than $15 \mathrm{~nm}$ have good permeability in cartilage (Bajpayee et al. 2015). In addition, since cartilage tissue carries a negative charge, metal/metal NPs with a positive electric potential are more likely to penetrate into cartilage. High cartilaginous permeability not only means higher utilization, but also means longer endochondral retention time. Metal/metal oxide NPs are usually able to remain in the joint cavity for a longer period of time, which can be regarded as a 'sustained-release agent' for metal ions to some extent.

\section{Nanoparticles that have shown cartilage protective effects}

\section{Gold and gold nanoparticles}

\section{Therapeutic mechanism of gold nanoparticles in osteoarthritis}

In past studies, gold NPs have shown good biocompatibility to most tissues in the human body (Cabuzu et al. 2015). Pascarelli et al. evaluated the toxicity of gold NPs with particle size of $50 \mathrm{~nm}$ to human osteoarthritis chondrocytes at different concentrations. They treated chondrocytes with gold NPs of $20 \mu \mathrm{M}, 40 \mu \mathrm{M}, 80 \mu \mathrm{M}, 160 \mu \mathrm{M}$, and $250 \mu \mathrm{M}$ for $24 \mathrm{~h}$. The results showed that chondrocyte viability was significantly inhibited (less than $40 \%$ ) at concentrations above $160 \mu \mathrm{M}$. The expression of inducible nitric oxide synthase (iNOS) and chondrolysis-related proteins, including MMP1/3/13 and ADAMTs-4/5, was increased (Pascarelli et al. 2013). In another study evaluating the cytotoxicity of gold NPs of different sizes to rabbit chondrocytes, only gold NPs at $13 \mathrm{~nm}$ significantly induced mitochondrial dysfunction and apoptosis compared with gold NPs at $3 \mathrm{~nm}$ and $45 \mathrm{~nm}$ (Huang et al. 2016). These results show that gold NPs also have good biocompatibility with cartilage.

Gold NPs have a good ability to resist oxidative stress. After treating RAW264.7 macrophages with 
poly-N-vinylpyrrolidone modified gold NPs $(50 \mathrm{~nm})$, Kingston et al. found that gold NPs of 5,25 and $50 \mu \mathrm{g} / \mathrm{ml}$ significantly reduced ROS production, and the inhibition effect was strongest at $25 \mu \mathrm{g} / \mathrm{ml}$ (Kingston et al. 2016). In another study of methamphetamine-induced liver injury treated with gold NPs $(7.4 \pm 1.6 \mathrm{~nm})$, gold NPs significantly reduced myeloperoxidase (MPO) activity, increased glutathione peroxidases (GPX) activity, and significantly reduced malondialdehyde production (de Carvalho et al. 2018). MPO is mainly expressed in neutrophils and monocytes and can catalyze the synthesis of hypochlorous acid. The decrease of MPO activity means the reduction of oxidative stress (Ndrepepa 2019). In addition to regulating the expression levels of oxidase and antioxidant enzyme, gold NPs themselves can also simulate the activities of various antioxidant enzymes such as GSH, SOD and peroxidase, and catalyze the decomposition of ROS (Dashtestani et al. 2019).

Khan et al. discussed the mechanism by which gold NPs inhibit inflammation. They used gold NPs, about $15 \mathrm{~nm}$ in size, to intraperitoneally inject a mouse model of collagen-induced arthritis once a week at a dose of $20 \mu \mathrm{g} /$ $\mathrm{kg}$. They collected serum after 20 days and found that the expressions of NF-kB, cyclooxygenase-2 (COX-2), TNF- $\alpha$, and IL- $1 \beta$ in the serum of the mice treated with gold NPs were significantly reduced compared with the negative control group. This suggests that gold NPs can inhibit inflammation by inhibiting the NF-kB pathway (Khan and Khan 2018). Synovitis plays an important role in the progression of osteoarthritis. Chondrodegradation products stimulate synovial fibroblasts and synovial macrophages to secrete cytokines such as IL- $1 \beta$ and TNF- $\alpha$, and promote chondrocyte secrete proteases such as MMP13 and ADAMTs-5 (Mathiessen and Conaghan 2017). Park et al. synthesized triamcinolone-gold NPs using gold NPs with a particle size of $20 \mathrm{~nm}$ and triam. The results showed that IL-1 $\beta$, IL-6, TNF- $\alpha$, MMP-1 and MMP-3 were down-regulated in a dose-dependent manner. While only triamcinolone-gold NPs significantly increased the expression of IL-4, Arg-1 and IL-10. This suggests that M1-type macrophages were transformed into M2-type macrophages under the treatment of triamcinolone-gold NPs (Park et al. 2020).

Although angiogenesis plays an important role in early cartilage development, vascular structure is not expressed in mature cartilage (Lingaraj et al. 2010, Zelzer et al. 2004). In osteoarthritis, the imbalance between angiogenesis and inhibitory factors leads to the advantage of angiogenesis, increases angiogenesis in synovium and meniscus, deep layer ossification of articular cartilage and osteophyte formation, which promotes cartilage destruction. Several past studies have shown that gold NPs have excellent antiangiogenic abilities (Darweesh et al. 2019) (Fig. 1).

However, gold NPs are still potentially dangerous. Zhang et al. (2019) treated mouse osteoblasts with $20 \mathrm{~nm}$ and $40 \mathrm{~nm}$ gold NPs at the concentration of $0.1 \mathrm{nM}$ and $1 \mathrm{nM}$, respectively. The results showed that alkaline phosphatase (ALP) activity of osteoblasts was increased and the number of calcium nodules was increased. The expressions of osteogenic specific genes Runx-2, BMP-2 and osteocalcin (OCN) were significantly increased. Phosphorylated Erk protein was increased. These results suggest that gold NPs promote osteogenesis of osteoblasts through
Fig. 1 Mechanism of gold nanoparticles in the treatment of osteoarthritis. After being ingested by chondrocytes and synovial cells, gold nanoparticles promote the decomposition of intracellular reactive oxygen species, inhibit the expression of inflammation-related genes, and inhibit the expression of angiogenesis related genes. Gold nanoparticles promote the transformation of pro-inflammatory M1-type macrophages to anti-inflammatory M2-type macrophages

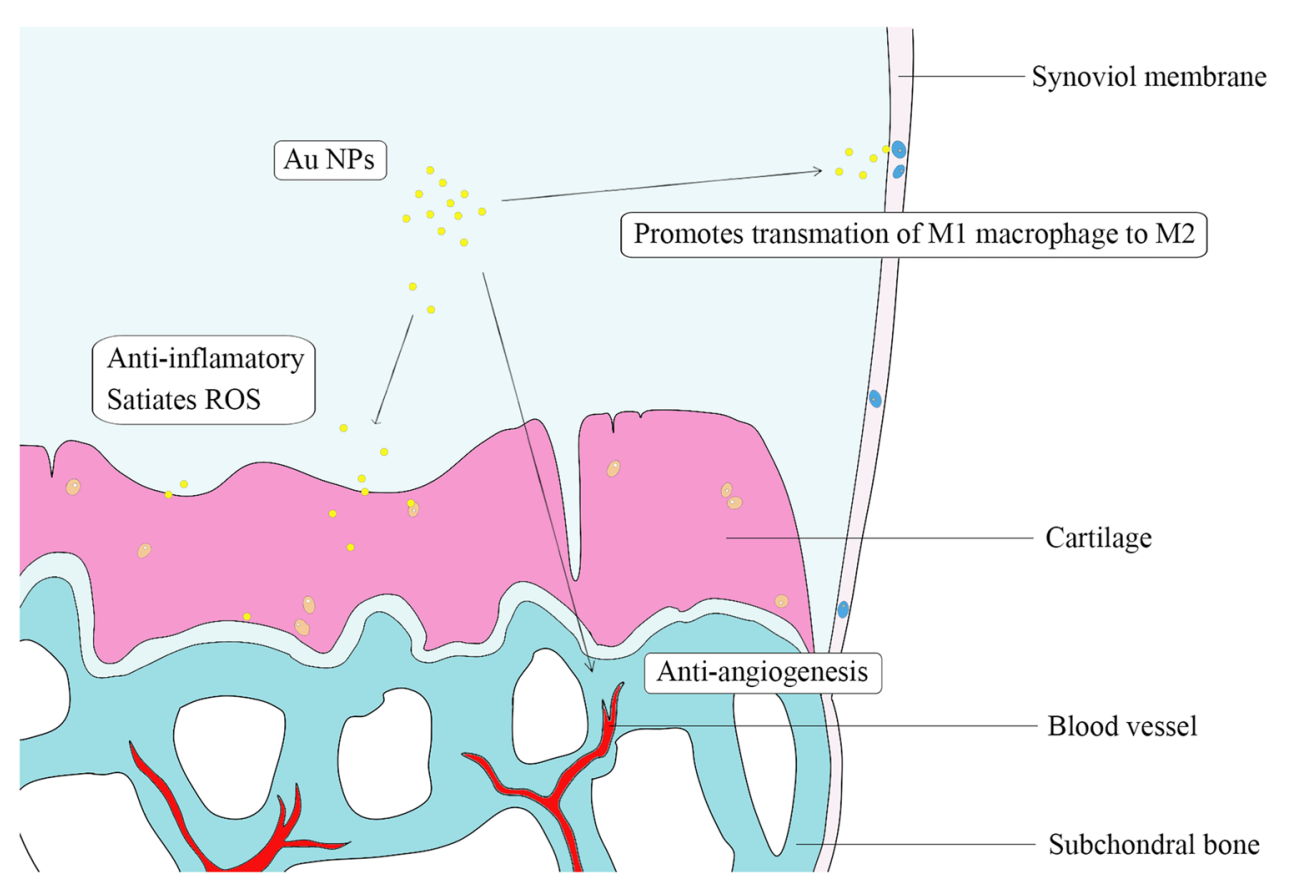


the Erk pathway (Zhang et al. 2014). This may aggravate osteophyte formation in patients with osteoarthritis.

\section{Progress of gold nanoparticles in the treatment of osteoarthritis}

In recent years, therapeutic agents related to gold NPs have been continuously developed. On the one hand, the way in which gold NPs can be delivered as therapeutic agents continues to improve. For example, using liposomes to enclose gold NPs absorbed with fish oil, which increase the stability (Sarkar et al. 2019). On the other hand, a growing number of drugs are being transported using gold NPs for their good biocompatibility and drug binding ability, such as hyaluronic acid, chondroitin sulfate, 2-[(aminocarbonyl)amino]-5-(4fluorophenyl)-3-thiophenecarboxamide (TPCA-1), and rutin (Dwivedi et al. 2015, Sansanaphongpricha et al. 2020, Gul et al. 2018, Wang et al. 2020).

Gold NPs have been widely used in the photothermal therapy of tumors due to their excellent photothermal conversion efficiency (Dwivedi et al. 2015, Sansanaphongpricha et al. 2020, Gul et al. 2018, Wang et al. 2020). Lee et al. designed poly(DL-lactic-co-glycolic acid) Au half-shell NPs carrying methotrexate (MTX) and binding arginylglycylaspartic acid peptides on the surface for targeting inflammatory synovium. Under the action of near-infrared resonance, MTX-PLGA-gold NPs realize photothermal controlled drug delivery (Lee et al. 2013). In summary, the potential of gold NPs in the treatment of osteoarthritis is constantly being explored.

\section{Manganese and manganese oxide nanoparticles}

\section{Therapeutic mechanism of manganese oxide nanoparticles in osteoarthritis}

Manganese, as a essential nutrient, is involved in various intracellular functions, such as the maintenance of manganese SOD (MnSOD) activity in the form of cofactor. Excess manganese accumulates in various tissues of the body, including the liver, bone and brain, the latter being the main target of manganese toxicity (Chen et al. 2018). Excess manganese ions can cause mitochondrial dysfunction by interfering with calcium homeostasis, and in addition, can increase the production of ROS (Tuschl et al. 2013).

Manganese oxide NPs play a dual role in oxidative stress. Alarifi et al. found that the particle size of $50 \mathrm{~nm}$ manganese tetroxide NPs significantly increased the production of ROS and inhibited the activities of SOD and GPX enzyme in SHSY5Y neuroblastoma cells at the concentration of $30 \mu \mathrm{g} /$ $\mathrm{ml}$ (Alarifi et al. 2017). Similarly, manganese tetroxide NPs with a particle size of about $20 \mathrm{~nm}$ significantly increased the production of ROS and apoptosis in PC12 neurons at a concentration of $5 \mu \mathrm{g} / \mathrm{ml}$ (Chen et al. 2020). After intraperitoneal injection of 30-60 nm manganese dioxide nanoparticles at a dose of $50 \mathrm{ug} / \mathrm{kg}$ in rats for 15 days, the production of ROS and apoptosis in hippocampal nerve cells were increased (Sadeghi et al. 2018).

These results suggest that manganese oxide NPs can induce the production of ROS to a certain extent. On the other hand, manganese oxide NPs can also play a role in anti-oxidative stress by simulating the activities of peroxidase and SOD (Tootoonchi et al. 2017). Singh et al. (2018) found that manganese tetroxide nanoparticles with a diameter of about $50 \mathrm{~nm}$ significantly reduced the production of ROS in HEK293T kidney cells and HeLa cells induced by $\mathrm{H}_{2} \mathrm{O}_{2}$. The accumulation of protein carbonyl, DNA double strand breakage and increased activity of apoptosis-related protein caspase- $3 / 7$ caused by ROS was also alleviated. Besides, the endogenous antioxidant enzyme system was not affected, including peroxiredoxin, CAT, SOD and glutathione (Singh et al. 2019). Similarly, Kuthati et al. pretreated bone marrow-derived macrophages with manganese oxide NPs with a particle size of $10 \mathrm{~nm}$, after which the production of ROS induced by PAM3CSK4 was significantly reduced (Kuthati et al. 2019). Manganese oxide NPs also reduced the expression of inflammation-related proteins, such as COX-2.

\section{Therapeutic effect of manganese oxide nanoparticles in osteoarthritis}

Polyethylene glycol (PEG) is a degradable polymer made up of repeated ethylene glycol units $\left[-\left(\mathrm{CH}_{2} \mathrm{CH}_{2} \mathrm{O}\right)_{n}\right]$, which can effectively reduce aggregation as a coating of NPs. The modification of low molecular weight PEG helped to maintain a smaller particle size, while the modification of high molecular weight PEG made the NPs more stable in vivo (Morgenstern et al. 2017; Abelha et al. 2019). Recently, Kumar et al. using potassium permanganate as manganese source and poly(allyl amine) hydrochloride (PAH) as reducing agent, prepared manganese dioxide NPs with particle size of $12.85 \mathrm{~nm}$, and increased its stability by conjugating with PEG (Kumar et al. 2019). PEG can bind to manganese dioxide nanoparticles in the form of coordination bonds. In addition, it can covalently bind with the $\mathrm{NH}_{2}$ group on PAH adsorbed on the surface of the manganese dioxide NPs (D'Souza and Shegokar 2016). They evaluated the efficacy of the NPs in the treatment of osteoarthritis. The results showed that PEG- $\mathrm{MnO}_{2}$ NPs showed no cytotoxicity to mouse chondrocytes, synovial cells, mesenchymal stem cells and bone marrow derived macrophages in the range of $0-100 \mu \mathrm{g} / \mathrm{mL}$. After treatment of $5 \mu \mathrm{g} / \mathrm{mL}$ PEG- $\mathrm{MnO}_{2}$ NPs, cartilage degradation products glucan aminoglycans and NO production were significantly reduced in cartilage grafts stimulated by IL- $1 \beta$. The expression of nitric oxide 
synthase, MMP-1, MMP-13 and ADAMTs5 were significantly decreased after treatment with $5 \mathrm{~g} / \mathrm{ml}$ PEG-MnO 2 NPs in chondrocyte stimulated by IL- $1 \beta$. The expression of anti-oxidative stress related genes, including GPX, MnSOD, extracellular SOD, CAT and Nrf2 pathway related genes, returned to normal levels. In vivo tests indicated that PEG$\mathrm{MnO}_{2}$ NPs remained in the articular cavity for more than 7 days without long-term adverse effects.

\section{Cerium and cerium oxide nanoparticles}

\section{Therapeutic mechanism of cerium oxide nanoparticles}

Because the liver is the main accumulation organ of NPs in the body, therapeutic studies based on the anti-oxidative stress effect of cerium oxide NPs are mainly focused on liver at present (Casals et al. 2020). Cerium oxide NPs also mimic the catalytic activity of antioxidant enzymes such as SOD and CAT. Adebayo et al. 2020 injected cerium NPs with particle size less than $10 \mathrm{~nm}$ into rats intraperitoneally at a dose of $100 \mu \mathrm{g} / \mathrm{kg}$ day and $200 \mu \mathrm{g} / \mathrm{kg}$ day for 8 days continuously, then intraperitoneal injection of diethylnitrosamine induces liver injury. The results showed that cerium oxide NPs significantly reduced the production of NO and lipid peroxides induced by diethylnitrosamine, decreased the activities of MPO and restored the activities of CAT activities and GPX. The apoptotic protein Bcl-2 was significantly reduced (Casals et al. 2020). Similarly, cerium oxide NPs alleviated oxidative damage induced by $\mathrm{H}_{2} \mathrm{O}_{2}$ and LPS in HepG2 hepatoma cells $(4.6 \pm 2 \mathrm{~nm} ; 10 \mu \mathrm{g} / \mathrm{ml}$ in vitro) (Carvajal et al. 2019). In a mouse model of cirrhosis, cerium oxide NPs reduced oxidative stress in portal vein endothelial cells in vitro and in vivo $(4-20 \mathrm{~nm} ; 1 \mu \mathrm{g} / \mathrm{ml}$ in vitro; $0.1 \mathrm{mg} /$ $\mathrm{kg}$ in vivo, i.t.) (Ribera et al. 2019).

The anti-oxidative stress ability of cerium oxide NPs may be derived from the conversion to $\mathrm{Ce}^{3+}$ and $\mathrm{Ce}^{4+}$. The conversion to $\mathrm{Ce}^{3+}$ to $\mathrm{Ce}^{4+}$ makes the cerium oxide NPs exhibit SOD-like activity, while the conversion to $\mathrm{Ce}^{4+}$ to $\mathrm{Ce}^{3+}$ makes the cerium oxide NPs exhibit CAT-like activity (Zheng et al. 2019).

\section{Therapeutic effect of cerium oxide nanoparticles in osteoarthritis}

Recently, Lin et al. (2020) evaluated the role of cerium oxide NPs with 30-60 nm size in osteoarthritis. The results showed that the cerium oxide NPs showed no cytotoxicity in the range of $0-0.02 \mu \mathrm{g} / \mathrm{ml}$. Compared with $0.01 \mu \mathrm{g} /$ $\mathrm{mL}$ cerium oxide NPs alone or $0.1 \%$ hyaluronic acid group, cerium oxide NPs combined with hyaluronic acid group significantly reduced the apoptosis of chondrocytes induced by $\mathrm{H}_{2} \mathrm{O}_{2}$, increased the expression of aggrecan (ACAN), Col1 $\alpha$ and Col $2 \alpha 1$, and increased the accumulation of sulfated proteoglycans (Zheng et al. 2019).

Notably, compared with other cells, cerium oxide NPs have been shown to inhibit chondrocyte activity at low concentrations, and its therapeutic effect in osteoarthritis needs to be further evaluated.

\section{Nanoparticles with the potential for cartilage protection}

\section{Magnesium and magnesium oxide nanoparticles}

\section{Effect of magnesium ions on osteoarthritis}

Magnesium is closely related to the regulation of cartilage function. High serum magnesium was inversely associated with radiographic severity of osteoarthritis (Zeng et al. 2015). Increased magnesium intake increases the thickness and volume of knee cartilage (Veronese et al. 2019). In patients with osteoarthritis, decreased magnesium intake was associated with decreased joint function and increased pain (Shmagel et al. 2018).

Magnesium ions play a protective role in osteoarthritis in several ways. Yao et al. cultured human osteoarthritis cartilage grafts with $20 \mathrm{mmol} / \mathrm{L} \mathrm{MgCI}_{2}$, and found that the production of MMP-13, ADAMTs-5, IL- 6 and IL- $1 \beta$ decreased, while the expression of COL $2 \alpha 1$ and ACAN increased. Intraarticular injection of $0.5 \mathrm{~mol} / \mathrm{L} \mathrm{MgCI}_{2}$ also showed cartilage protective and antisynovitis effects in a mouse model of osteoarthritis (Yao et al. 2019). These evidence suggest that magnesium ions can inhibit inflammation, reduce cartilage degradation and promote cartilage synthesis in osteoarthritis. In another study, magnesium ions suppressed the expression of osteogenic specific genes ALP, Runx2, and COL10 $\alpha 1$, and increased the expression of SOX9. In this process, the phosphorylation of Erk protein was inhibited, which inhibited the activation of Erk pathway (Yue et al. 2019). This suggests that magnesium ions inhibits the hypertrophic ossification of chondrocytes. In addition, the presence of magnesium ions can also inhibit autophagy of chondrocytes.

\section{Therapeutic effect of magnesium oxide nanoparticles}

At present, there are few studies related to the therapeutic effect of magnesium oxide NPs. Nodeh et al. evaluated the effects of dispersed magnesium oxide NPs with a size of about $100 \mathrm{~nm}$ on islet cells. The results showed that the levels of ROS and lipid peroxidation were significantly decreased under the treatment of 10 and $100 \mu \mathrm{g} / \mathrm{ml} \mathrm{mag-}$ nesium oxide NPs. One hundred microgram $/ \mathrm{ml}$ magnesium oxide NPs significantly increased the cell viability, 
decreased the expression of caspase-3/9, and inhibited the apoptosis of islet cells (Moeini-Nodeh et al. 2017). Magnesium oxide NPs have the ability to inhibit oxidative stress.

Compared with normal joint fluid, joint fluid in patients with osteoarthritis is more acidic. Magnesium oxide NPs was degraded to $\mathrm{Mg}(\mathrm{OH})_{2}$ and further converted to $\mathrm{MgCI}_{2}$ (Suryavanshi et al. 2017). In this process, magnesium oxide NPs may also play a role in improving the $\mathrm{pH}$ of the joint fluid while producing biologically active magnesium ions. In conclusion, magnesium oxide NPs have certain potential for the treatment of osteoarthritis (Fig. 2).

\section{Zinc and zinc oxide nanoparticles}

\section{Effect of zinc ions on osteoarthritis}

Zinc ions may play a dual role in the progression of osteoarthritis. According to studies, high serum zinc is associated with a reduced risk of cartilage calcification (He et al. 2020). However, there is also a study which finds an inherited high zinc status increased the risk of osteoarthritis (Zhou et al. 2021).

As a cofactor of matrix metalloproteinase and thrombin proteinase, zinc plays an important role in cartilage destruction (Malemud 2019). The expression of $\mathrm{Zn} 2^{+}$transporter ZIP8 is increased in osteoarthritis cartilage. The increase in ZIP8 expression results in the increase in intracellular
$\mathrm{Zn} 2^{+}$content, and activates downstream transcription factor MTF1, which upregulates the expression of matrix-degrading enzymes, such as MMP-3 and MMP-13 (Kim et al. 2014). On the other hand, zinc ions have a protective effect on cartilage under oxidative stress. As reported by Huang et al., zinc ions reversed the decrease in the expression of energy metabolism-related proteins (including glucose transporter-1, hexokinase-2, pyruvate dehydrogenase E1 component subunit alpha) and autophagy related proteins (including ATG5/7, LC3-II, PINK1) induced by iodoacetic acid in SW1353 osteosarcoma cells (Huang et al. 2020, 2018). The decrease of GPX1 and Mn-SOD expression was saved, while increase of IL-1 $\beta$ and MMP-13 expression of was inhibited. In addition, Nrf2 and its upstream kinase phosphorylated Akt were increased. Nrf2 plays an important protective role in the progression of osteoarthritis by inhibiting oxidative stress (Loeser et al. 2016). In another study, adding zinc ions to the drinking water of iodoacetic acid-induced osteoarthritis mice reduced cartilage damage (Huang et al. 2018).

\section{Therapeutic effect of zinc oxide nanoparticles}

Zinc oxide NPs also have anti-oxidative stress, anti-inflammatory and other effects. The activities of SOD, peroxidase and CAT in liver of gout mice were recovered after oral administration of zinc oxide NPs with a diameter of $37 \mathrm{~nm}$. The reaction products of ROS and thiobarbituric acid
Fig. 2 Potential mechanism of magnesium oxide nanoparticles in the treatment of osteoarthritis. Magnesium oxide nanoparticles promote scavenging of reactive oxygen species in cells. Magnesium oxide nanoparticles are degraded to $\mathrm{Mg}(\mathrm{OH})_{2}$ in the synovial fluid, which releases magnesium ions while neutralizing the acidic environment in the joint cavity, promotes the synthesis of cartilage matrix, and inhibits the expression of osteogenic specific genes and inflammation-related genes

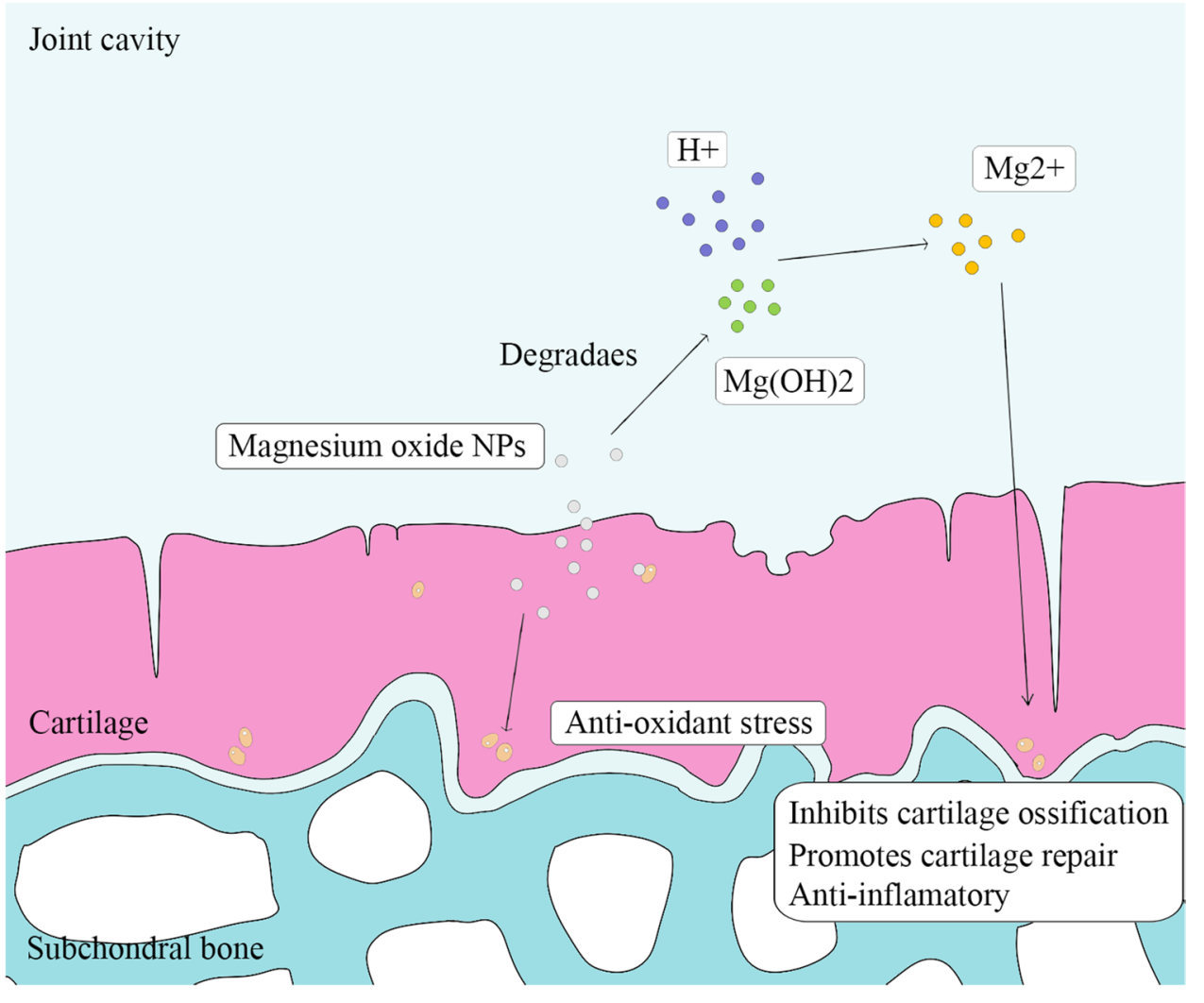


reactive substances were reduced too (Kiyani et al. 2019). On the anti-inflammatory effect, zinc oxide NPs with particle size of 200 significantly inhibited the NF-kB pathway in the range of $0-10 \mu \mathrm{g} / \mathrm{mL}$, and reduced the expression of COX-2 and iNOS (Kim and Jeong 2015). The study of Khader and Arinzeh (2020) suggested the effect of zinc oxide NPs on chondrocytes (Kim and Jeong 2015). Polycaprolactone (PCL) is an aliphatic polyester made up of repeated hexanoate units that are widely used in the long term delivery of drugs. Khader and Arinzeh (2020) dissolved 80,000 molecular weight of polycaprolactone (PCL) $\left[-\left(\mathrm{C}_{6} \mathrm{H}_{10} \mathrm{O}_{2}\right)_{n}\right]$ and zinc oxide NPs with an average particle size of $63 \mathrm{~nm}$ in an organic solvent, and synthesized a composite scaffold capable of sustainably releasing zinc oxide NPs by electrospinning. Then the scaffold was inserted into the cell plate in the form of a disc, and human mesenchymal stem cells were seeded on it. The results showed that cells growing on scaffolds containing $1 \%$ or $2.5 \%$ zinc oxide NPs expressed higher levels of SOX9, ACAN and Col2 after 7, 14 , and 28 days of culture in cartilage medium. After 28 days of culture in growth medium, ALP activity and hydroxyproline production were higher in cells grown on scaffolds containing $5 \%$ or $10 \%$ zinc oxide NPs. The expression of the osteogenic genes Runx-2, OCN, Osterix, and VEGF in cells grown on scaffolds containing $1 \%$ or $2.5 \%$ zinc oxide NPs was similar to that in the control group.

\section{Conclusion}

In recent years, the green synthesis of metal/metal oxide NPs has attracted more and more attention. Ahn et al. synthesized gold NPs with skate (Dipturus chilensis) cartilage waste extract as a green reducing agent (Ahn et al. 2018). Ogunyemi et al. synthesized magnesium oxide and manganese dioxide NPs with chamomile extracts (Ogunyemi et al. 2019). NPs made from bacteria and fungi or made through plant extract are safer than traditional chemical synthesis methods, reducing the use of toxic chemicals. Meanwhile, the green synthesis process is usually simpler and uses less energy (Singh et al. 2016). Compared with expensive chemicals, the use of green plant extracts for synthesis is also more cost-effective.

Nanotechnology holds broad promise in the treatment of osteoarthritis. Compared with drugs, NPs are more stable in the body and have a longer half-life, so they are often used as carriers to deliver drugs. Meanwhile, NPs are also excellent sustained-release systems, which can continuously and stably release the loaded drugs. NPs have a long retention time in the joint cavity (Kumar et al. 2019; Liu et al. 2019). Cartilage damage and synovial inflammation play an important role in the progression of osteoarthritis. Type II collagen is the main component of cartilage matrix, and by binding antibodies for type II collagen to the surface of NPs, the targeted uptake of NPs by damaged articular cartilage can be promoted (Noyori et al. 1994). The increased proportion of angiogenic endothelial cells in the inflammatory synovium increases the expression of $\alpha v \beta 3$ integrins. Modification of specific ligand such as vitronectin enables NPs to target the inflammatory synovium (Zhou et al. 2009). Systemic administration that does not intrude into the joint space, such as oral or intravenous administration, has the advantage of reducing discomfort and the risk of joint infection. Targeted modification of NPs makes systemic drug delivery more promising, reducing the dose needed to trigger therapeutic effects while reducing the side effects of untargeted absorption. Metal/ metal oxide NPs have the above advantages, but also can simulate the activity of antioxidant, thus exerting the role of anti-oxidative stress. In addition, metal/metal oxide NPs also have good antimicrobial activity, which makes them potentially promising for treatment of septic arthritis. The biocompatibility of NPs is greatly affected by the degradability of NPs and the difficulty of removing the degradation products. Metal/metal oxide NPs and their degradation release metal ions are easy to accumulate in vivo, which may lead to potential toxicity. Sun et al. found that the ability of metal nanoparticles to induce the production of reactive oxygen species was positively correlated with the amount of positive charge carried by nanoparticles and the degree of hydrophobicity (Sun et al. 2018). Although metal/metal oxide NPs have not shown significant toxicity at therapeutic doses in the literature reviewed here, their long-term safety needs to be further monitored. In summary, in this article, we summarize the current status of metal/metal oxide NPs in the treatment of osteoarthritis and propose some promising NPs.

Author contribution Junchao Luo, Yin Zhang, and Senbo Zhu wrote the manuscript which was revised and reviewed by Yu Tong, Lichen Ji, Wei Zhang, Qiong Zhang and Qing Bi. All authors read and approved the final version of the manuscript and all data were generated in-house and that no paper mill was used.

Funding "The application prospect of metal/metal oxide nanoparticles in the treatment of osteoarthritis" (No. NSAP-D-21-00222R1) was funded by Medical Health Science and Technology Project of Zhejiang Provincial Health Commission (2021KY028).

Data availability Not applicable.

\section{Declarations}

Ethics approval This paper complies with ethical standards and does not require ethical approval.

Consent to participate Not applicable. 
Consent for publication All authors agree to publish this paper.

Competing interests The authors declare no competing interests.

Open Access This article is licensed under a Creative Commons Attribution 4.0 International License, which permits use, sharing, adaptation, distribution and reproduction in any medium or format, as long as you give appropriate credit to the original author(s) and the source, provide a link to the Creative Commons licence, and indicate if changes were made. The images or other third party material in this article are included in the article's Creative Commons licence, unless indicated otherwise in a credit line to the material. If material is not included in the article's Creative Commons licence and your intended use is not permitted by statutory regulation or exceeds the permitted use, you will need to obtain permission directly from the copyright holder. To view a copy of this licence, visit http://creativecommons.org/licenses/by/4.0/.

\section{References}

Abelha TF, Neumann PR, Holthof J, Dreiss CA, Alexander C, Green M, Dailey LA (2019) Low molecular weight PEG-PLGA polymers provide a superior matrix for conjugated polymer nanoparticles in terms of physicochemical properties, biocompatibility and optical/photoacoustic performance. J Mater Chem B 7(33):5115-5124. https://doi.org/10.1039/c9tb00937j ([Journal Article; Research Support, Non-U.S. Gov't])

Abramoff B, Caldera FE (2020) Osteoarthritis: pathology, diagnosis, and treatment options. Med Clin North Am 104(2):293-311. https://doi.org/10.1016/j.mcna.2019.10.007 ([Journal Article; Review])

Adebayo OA, Akinloye O, Adaramoye OA (2020) Cerium oxide nanoparticles attenuate oxidative stress and inflammation in the liver of diethylnitrosamine-treated mice. Biol Trace Elem Res 193(1):214-225. https://doi.org/10.1007/s12011-019-01696-5 ([Journal Article])

Agarwal H, Nakara A, Shanmugam VK (2019) Anti-inflammatory mechanism of various metal and metal oxide nanoparticles synthesized using plant extracts: a review. Biomed Pharmacother 109:2561-2572. https://doi.org/10.1016/j.biopha.2018.11.116 ([Journal Article; Review])

Ahn EY, Lee YJ, Choi SY, Im AR, Kim YS, Park Y (2018) Highly stable gold nanoparticles green-synthesized by upcycling cartilage waste extract from yellow-nose skate (Dipturus chilensis) and evaluation of its cytotoxicity, haemocompatibility and antioxidant activity. Artif Cells Nanomed Biotechnol 46(sup2):1108 1119. https://doi.org/10.1080/21691401.2018.1479710 ([Journal Article])

Alarifi S, Ali D, Alkahtani S (2017) Oxidative stress-induced DNA damage by manganese dioxide nanoparticles in human neuronal cells. Biomed Res Int 2017:5478790. https://doi.org/10.1155/ 2017/5478790 ([Journal Article])

Ashrafi HA, Naserzadeh P, Mortazavian AM, Mehravi B, Ashtari K, Seydi E, Salimi A (2019) Comparison of the effects of $\mathrm{MnO}(2)$ $\mathrm{NPs}$ and $\mathrm{MnO}(2)-\mathrm{MPs}$ on mitochondrial complexes in different organs. Toxicol Mech Methods 29(2):86-94. https://doi.org/10. 1080/15376516.2018.1512693 ([Comparative Study; Journal Article])

Bai Y, Gong X, Dou C, Cao Z, Dong S (2019) Redox control of chondrocyte differentiation and chondrogenesis. Free Radic Biol Med 132:83-89. https://doi.org/10.1016/j.freeradbiomed.2018.10.443 ([Journal Article; Research Support, Non-U.S. Gov't; Review])

Bajpayee AG, Scheu M, Grodzinsky AJ, Porter RM (2015) A rabbit model demonstrates the influence of cartilage thickness on intra-articular drug delivery and retention within cartilage. J Orthop Res 33(5):660-667. https://doi.org/10.1002/jor.22841 ([Journal Article; Research Support, Non-U.S. Gov't])

Binnemars-Postma KA, Ten HH, Storm G, Prakash J (2016) Differential uptake of nanoparticles by human M1 and M2 polarized macrophages: protein corona as a critical determinant. Nanomedicine (Lond) 11(22):2889-2902. https://doi.org/10.2217/nnm-20160233 ([Journal Article])

Bolduc JA, Collins JA, Loeser RF (2019) Reactive oxygen species, aging and articular cartilage homeostasis. Free Radic Biol Med 132:73-82. https://doi.org/10.1016/j.freeradbiomed.2018.08.038 ([Journal Article; Research Support, N.I.H., Extramural; Research Support, Non-U.S. Gov't; Review])

Burgess S, Wang Z, Vishnyakov A, Neimark AV (2020) Adhesion, intake, and release of nanoparticles by lipid bilayers. J Colloid Interface Sci 561:58-70. https://doi.org/10.1016/j.jcis.2019.11. 106 ([Journal Article])

Cabuzu D, Cirja A, Puiu R, Grumezescu AM (2015) Biomedical applications of gold nanoparticles. Curr Top Med Chem 15(16):16051613. https://doi.org/10.2174/1568026615666150414144750 ([Journal Article; Research Support, Non-U.S. Gov't; Review])

Carballo CB, Nakagawa Y, Sekiya I, Rodeo SA (2017) Basic science of articular cartilage. Clin Sports Med 36(3):413-425. https:// doi.org/10.1016/j.csm.2017.02.001 ([Journal Article; Review])

Carvajal S, Perramón M, Casals G, Oró D, Ribera J, Morales-Ruiz M, Casals E, Casado P, Melgar-Lesmes P, Fernández-Varo G, Cutillas P, Puntes V, Jiménez W (2019) Cerium oxide nanoparticles protect against oxidant injury and interfere with oxidative mediated kinase signaling in human-derived hepatocytes. Int J Mol Sci 20(23):5959. https://doi.org/10.3390/ijms20235959 ([Journal Article])

Casals E, Zeng M, Parra-Robert M, Fernández-Varo G, Morales-Ruiz M, Jiménez W, Puntes V, Casals G (2020) Cerium oxide nanoparticles: advances in biodistribution, toxicity, and preclinical exploration. Small 16(20):e1907322. https://doi.org/10.1002/ smll.201907322 ([Journal Article; Research Support, Non-U.S. Gov't; Review])

Chen P, Bornhorst J, Aschner M (2018) Manganese metabolism in humans. Front Biosci (landmark Ed) 23:1655-1679. https://doi. org/10.2741/4665 ([Journal Article; Research Support, N.I.H., Extramural; Research Support, Non-U.S. Gov't; Review])

Chen X, Wu G, Zhang Z, Ma X, Liu L (2020) Neurotoxicity of Mn(3) $\mathrm{O}(4)$ nanoparticles: apoptosis and dopaminergic neurons damage pathway. Ecotoxicol Environ Saf 188:109909. https://doi.org/10. 1016/j.ecoenv.2019.109909 ([Journal Article])

Coryell PR, Diekman BO, Loeser RF (2021) Mechanisms and therapeutic implications of cellular senescence in osteoarthritis. Nat Rev Rheumatol 17(1):47-57. https://doi.org/10.1038/s41584-02000533-7 ([Comparative Study; Journal Article; Research Support, N.I.H., Extramural; Review])

Darweesh RS, Ayoub NM, Nazzal S (2019) Gold nanoparticles and angiogenesis: molecular mechanisms and biomedical applications. Int J Nanomedicine 14:7643-7663. https://doi.org/10.2147/IJN. S223941 ([Journal Article; Review])

Dashtestani F, Ghourchian H, Najafi A (2019) Silver-gold-apoferritin nanozyme for suppressing oxidative stress during cryopreservation. Mater Sci Eng C Mater Biol Appl 94:831-840. https://doi. org/10.1016/j.msec.2018.10.008 ([Journal Article])

de Carvalho TG, Garcia VB, de Araújo AA, Da SGL, Silva H, Guerra G, de Castro ME, de Carvalho LR, Da SCD, Cruz LJ, Chan AB, de Araújo JR (2018) Spherical neutral gold nanoparticles improve anti-inflammatory response, oxidative stress and fibrosis in alcohol-methamphetamine-induced liver injury in rats. Int $\mathrm{J}$ Pharm 548(1):1-14. https://doi.org/10.1016/j.ijpharm.2018.06. 008 ([Journal Article]) 
Ding L, Yao C, Yin X, Li C, Huang Y, Wu M, Wang B, Guo X, Wang Y, Wu M (2018) Size, shape, and protein corona determine cellular uptake and removal mechanisms of gold nanoparticles. Small 14(42):e1801451. https://doi.org/10.1002/smll.201801451 ([Journal Article; Research Support, Non-U.S. Gov't])

D'Souza AA, Shegokar R (2016) Polyethylene glycol (PEG): a versatile polymer for pharmaceutical applications. Expert Opin Drug Deliv 13(9):1257-1275. https://doi.org/10.1080/17425247.2016. 1182485 ([Journal Article; Review])

Dwivedi P, Nayak V, Kowshik M (2015) Role of gold nanoparticles as drug delivery vehicles for chondroitin sulfate in the treatment of osteoarthritis. Biotechnol Prog 31(5):1416-1422. https://doi. org/10.1002/btpr.2147 ([Journal Article; Research Support, NonU.S. Gov't])

Farvadi F, Ghahremani MH, Hashemi F, Reza HM, Raoufi M, Zanganeh S, Atyabi F, Dinarvand R, Mahmoudi M (2018) Cell shape affects nanoparticle uptake and toxicity: an overlooked factor at the nanobio interfaces. J Colloid Interface Sci 531:245-252. https://doi.org/10.1016/j.jcis.2018.07.013 ([Journal Article])

Gul A, Kunwar B, Mazhar M, Faizi S, Ahmed D, Shah MR, Simjee SU (2018) Rutin and rutin-conjugated gold nanoparticles ameliorate collagen-induced arthritis in rats through inhibition of NF- $\mathrm{KB}$ and iNOS activation. Int Immunopharmacol 59:310-317. https://doi. org/10.1016/j.intimp.2018.04.017 ([Journal Article])

He H, Wang Y, Yang Z, Ding X, Yang T, Lei G, Li H, Xie D (2020) Association between serum zinc and copper concentrations and copper/zinc ratio with the prevalence of knee chondrocalcinosis: a cross-sectional study. BMC Musculoskelet Disord 21(1):97. https://doi.org/10.1186/s12891-020-3121-z ([Journal Article])

Huang H, Quan YY, Wang XP, Chen TS (2016) Gold nanoparticles of diameter $13 \mathrm{~nm}$ induce apoptosis in rabbit articular chondrocytes. Nanoscale Res Lett 11(1):249. https://doi.org/10.1186/s11671016-1461-2 ([Journal Article])

Huang LW, Huang TC, Hu YC, Hsieh BS, Chiu PR, Cheng HL, Chang KL (2020) Zinc protects chondrocytes from monosodium iodoacetate-induced damage by enhancing ATP and mitophagy. Biochem Biophys Res Commun 521(1):50-56. https://doi.org/10.1016/j. bbrc.2019.10.066 ([Journal Article; Research Support, Non-U.S. Gov't])

Huang TC, Chang WT, Hu YC, Hsieh BS, Cheng HL, Yen JH, Chiu PR, Chang KL (2018) Zinc protects articular chondrocytes through Changes in Nrf2-mediated antioxidants, cytokines and matrix metalloproteinases. Nutrients 10(4):471. https://doi.org/ 10.3390/nu10040471 ([Journal Article])

Hunter DJ, Bierma-Zeinstra S (2019) Osteoarthritis. Lancet 393(10182):1745-1759. https://doi.org/10.1016/S0140-6736(19) 30417-9 ([Journal Article; Review])

Jiang Y, Huo S, Mizuhara T, Das R, Lee YW, Hou S, Moyano DF, Duncan B, Liang XJ, Rotello VM (2015) The interplay of size and surface functionality on the cellular uptake of sub-10 nm gold nanoparticles. ACS Nano 9(10):9986-9993. https://doi.org/ 10.1021/acsnano.5b03521 ([Journal Article; Research Support, N.I.H., Extramural; Research Support, Non-U.S. Gov't])

Khader A, Arinzeh TL (2020) Biodegradable zinc oxide composite scaffolds promote osteochondral differentiation of mesenchymal stem cells. Biotechnol Bioeng 117(1):194-209. https://doi.org/ 10.1002/bit.27173 ([Journal Article; Research Support, Non-U.S. Gov't; Research Support, U.S. Gov't, Non-P.H.S.])

Khan MA, Khan MJ (2018) Nano-gold displayed anti-inflammatory property via NF-kB pathways by suppressing COX-2 activity. Artif Cells Nanomed Biotechnol 46(sup1):1149-1158. https:// doi.org/10.1080/21691401.2018.1446968 ([Journal Article])

Kim JH, Jeon J, Shin M, Won Y, Lee M, Kwak JS, Lee G, Rhee J, Ryu JH, Chun CH, Chun JS (2014) Regulation of the catabolic cascade in osteoarthritis by the zinc-ZIP8-MTF1 axis. Cell
156(4):730-743. https://doi.org/10.1016/j.cell.2014.01.007 ([Journal Article; Research Support, Non-U.S. Gov't])

Kim MH, Jeong HJ (2015) Zinc oxide nanoparticles suppress LPSinduced NF- $\mathrm{\kappa B}$ activation by inducing A20, a negative regulator of NF- $\mathrm{KB}$, in RAW 264.7 macrophages. J Nanosci Nanotechnol 15(9):6509-6515. https://doi.org/10.1166/jnn.2015.10319 ([Journal Article; Research Support, Non-U.S. Gov't])

Kingston M, Pfau JC, Gilmer J, Brey R (2016) Selective inhibitory effects of 50-nm gold nanoparticles on mouse macrophage and spleen cells. J Immunotoxicol 13(2):198-208. https://doi.org/10. 3109/1547691X.2015.1035819 ([Journal Article; Research Support, N.I.H., Extramural])

Kiyani MM, Butt MA, Rehman H, Ali H, Hussain SA, Obaid S, Arif HM, Mahmood T, Bokhari S (2019) Antioxidant and anti-gout effects of orally administered zinc oxide nanoparticles in gouty mice. J Trace Elem Med Biol 56:169-177. https://doi.org/10. 1016/j.jtemb.2019.08.012 ([Journal Article])

Krishnan Y, Grodzinsky AJ (2018) Cartilage diseases. Matrix Biol 71-72:51-69. https://doi.org/10.1016/j.matbio.2018.05.005 ([Journal Article; Research Support, N.I.H., Extramural; Research Support, U.S. Gov't, Non-P.H.S.; Review])

Kumar S, Adjei IM, Brown SB, Liseth O, Sharma B (2019) Manganese dioxide nanoparticles protect cartilage from inflammation-induced oxidative stress. Biomaterials 224:119467. https://doi.org/10. 1016/j.biomaterials.2019.119467 ([Journal Article; Research Support, N.I.H., Extramural; Research Support, Non-U.S. Gov't])

Kuthati Y, Busa P, Goutham DV, Wong CS (2019) Manganese oxide nanozymes ameliorate mechanical allodynia in a rat model of partial sciatic nerve-transection induced neuropathic pain. Int J Nanomedicine 14:10105-10117. https://doi.org/10.2147/IJN. S225594 ([Journal Article])

Lee SM, Kim HJ, Ha YJ, Park YN, Lee SK, Park YB, Yoo KH (2013) Targeted chemo-photothermal treatments of rheumatoid arthritis using gold half-shell multifunctional nanoparticles. ACS Nano 7(1):50-57. https://doi.org/10.1021/nn301215q ([Journal Article; Research Support, Non-U.S. Gov't])

Lepetsos P, Papavassiliou KA, Papavassiliou AG (2019) Redox and NF- $\kappa B$ signaling in osteoarthritis. Free Radic Biol Med 132:90 100. https://doi.org/10.1016/j.freeradbiomed.2018.09.025 ([Journal Article; Review])

Li J, Li JJ, Zhang J, Wang X, Kawazoe N, Chen G (2016) Gold nanoparticle size and shape influence on osteogenesis of mesenchymal stem cells. Nanoscale 8(15):7992-8007. https://doi.org/10. 1039/c5nr08808a ([Journal Article; Research Support, Non-U.S. Gov't])

Li Y, Yue T, Yang K, Zhang X (2012) Molecular modeling of the relationship between nanoparticle shape anisotropy and endocytosis kinetics. Biomaterials 33(19):4965-4973. https://doi.org/ 10.1016/j.biomaterials.2012.03.044 ([Journal Article; Research Support, Non-U.S. Gov't])

Li Y, Zhang X, Cao D (2015) Nanoparticle hardness controls the internalization pathway for drug delivery. Nanoscale 7(6):2758-2769. https://doi.org/10.1039/c4nr05575f ([Journal Article; Research Support, Non-U.S. Gov't])

Liguori I, Russo G, Curcio F, Bulli G, Aran L, Della-Morte D, Gargiulo G, Testa G, Cacciatore F, Bonaduce D, Abete P (2018) Oxidative stress, aging, and diseases. Clin Interv Aging 13:757-772. https:// doi.org/10.2147/CIA.S158513 ([Journal Article; Review])

Lin YW, Fang CH, Meng FQ, Ke CJ, Lin FH (2020) Hyaluronic acid loaded with cerium oxide nanoparticles as antioxidant in hydrogen peroxide induced chondrocytes injury: an in vitro osteoarthritis model. Molecules 25(19):4407. https://doi.org/10.3390/molec ules25194407 ([Journal Article])

Lingaraj K, Poh CK, Wang W (2010) Vascular endothelial growth factor (VEGF) is expressed during articular cartilage growth and 
re-expressed in osteoarthritis. Ann Acad Med Singap 39(5):399403 ([Journal Article])

Liu X, Corciulo C, Arabagian S, Ulman A, Cronstein BN (2019) Adenosine-functionalized biodegradable PLA-b-PEG nanoparticles ameliorate osteoarthritis in rats. Sci Rep 9(1):7430. https:// doi.org/10.1038/s41598-019-43834-y ([Journal Article; Research Support, N.I.H., Extramural; Research Support, Non-U.S. Gov't])

Loeser RF, Collins JA, Diekman BO (2016) Ageing and the pathogenesis of osteoarthritis. Nat Rev Rheumatol 12(7):412-420. https:// doi.org/10.1038/nrrheum.2016.65 ([Journal Article; Research Support, N.I.H., Extramural; Review])

Malemud CJ (2019) Inhibition of MMPs and ADAM/ADAMTS. Biochem Pharmacol 165:33-40. https://doi.org/10.1016/j.bcp.2019. 02.033 ([Journal Article; Research Support, N.I.H., Extramural; Research Support, Non-U.S. Gov't; Review])

Mangalampalli B, Dumala N, Grover P (2018) Allium cepa root tip assay in assessment of toxicity of magnesium oxide nanoparticles and microparticles. J Environ Sci (China) 66:125-137. https://doi. org/10.1016/j.jes.2017.05.012 ([Journal Article])

Martínez DTI, Vida C, Garrido A, De la Fuente M (2020) Redox parameters as markers of the rate of aging and predictors of life span. J Gerontol A Biol Sci Med Sci 75(4):613-620. https://doi. org/10.1093/gerona/glz033 ([Journal Article; Research Support, Non-U.S. Gov't])

Mathiessen A, Conaghan PG (2017) Synovitis in osteoarthritis: current understanding with therapeutic implications. Arthritis Res Ther 19(1):18. https://doi.org/10.1186/s13075-017-1229-9 ([Journal Article; Review])

Moeini-Nodeh S, Rahimifard M, Baeeri M, Abdollahi M (2017) Functional improvement in rats' pancreatic islets using magnesium oxide nanoparticles through antiapoptotic and antioxidant pathways. Biol Trace Elem Res 175(1):146-155. https://doi.org/10. 1007/s12011-016-0754-8 ([Journal Article])

Morgenstern J, Baumann P, Brunner C, Hubbuch J (2017) Effect of PEG molecular weight and PEGylation degree on the physical stability of PEGylated lysozyme. Int J Pharm 519(1-2):408-417. https://doi.org/10.1016/j.ijpharm.2017.01.040 ([Journal Article])

Mukherjee K, Acharya K (2018) Toxicological effect of metal oxide nanoparticles on soil and aquatic habitats. Arch Environ Contam Toxicol 75(2):175-186. https://doi.org/10.1007/s00244-0180519-9 ([Journal Article; Review])

Murugan K, Choonara YE, Kumar P, Bijukumar D, du Toit LC, Pillay V (2015) Parameters and characteristics governing cellular internalization and trans-barrier trafficking of nanostructures. Int $\mathbf{J}$ Nanomedicine 10:2191-2206. https://doi.org/10.2147/IJN.S75615 ([Journal Article; Review])

Ndrepepa G (2019) Myeloperoxidase-a bridge linking inflammation and oxidative stress with cardiovascular disease. Clin Chim Acta 493:36-51. https://doi.org/10.1016/j.cca.2019.02.022 ([Journal Article; Review])

Noyori K, Koshino T, Takagi T, Okamoto R, Jasin HE (1994) Binding characteristics of antitype II collagen antibody to the surface of diseased human cartilage as a probe for tissue damage. J Rheumatol 21(2):293-296 ([Journal Article; Research Support, Non-U.S. Gov't; Research Support, U.S. Gov't, P.H.S.])

Ogunyemi SO, Zhang F, Abdallah Y, Zhang M, Wang Y, Sun G, Qiu W, Li B (2019) Biosynthesis and characterization of magnesium oxide and manganese dioxide nanoparticles using Matricaria chamomilla L extract and its inhibitory effect on Acidovorax oryzae strain RS-2. Artif Cells Nanomed Biotechnol 47(1):2230 2239. https://doi.org/10.1080/21691401.2019.1622552 ([Journal Article])

Pareek V, Bhargava A, Bhanot V, Gupta R, Jain N, Panwar J (2018) Formation and characterization of protein corona around nanoparticles: a review. J Nanosci Nanotechnol 18(10):6653-6670. https:// doi.org/10.1166/jnn.2018.15766 ([Journal Article; Review])
Park JY, Kwon S, Kim SH, Kang YJ, Khang D (2020) Triamcinolonegold nanoparticles repolarize synoviocytes and macrophages in an inflamed synovium. ACS Appl Mater Interfaces 12(35):3893638949. https://doi.org/10.1021/acsami.0c09842 ([Journal Article])

Pascarelli NA, Moretti E, Terzuoli G, Lamboglia A, Renieri T, Fioravanti A, Collodel G (2013) Effects of gold and silver nanoparticles in cultured human osteoarthritic chondrocytes. J Appl Toxicol 33(12):1506-1513. https://doi.org/10.1002/jat.2912 ([Journal Article])

Rhoads JP, Major AS (2018) How oxidized low-density lipoprotein activates inflammatory responses. Crit Rev Immunol 38(4):333342. https://doi.org/10.1615/CritRevImmunol.2018026483 ([Journal Article; Research Support, N.I.H., Extramural; Research Support, U.S. Gov't, Non-P.H.S.; Review])

Ribera J, Rodríguez-Vita J, Cordoba B, Portolés I, Casals G, Casals E, Jiménez W, Puntes V, Morales-Ruiz M (2019) Functionalized cerium oxide nanoparticles mitigate the oxidative stress and pro-inflammatory activity associated to the portal vein endothelium of cirrhotic rats. PLoS One 14(6):e218716. https://doi. org/10.1371/journal.pone.0218716 ([Journal Article; Research Support, Non-U.S. Gov't])

Ridolfi A, Caselli L, Montis C, Mangiapia G, Berti D, Brucale M, Valle F (2020) Gold nanoparticles interacting with synthetic lipid rafts: an AFM investigation. J Microsc 280(3):194-203. https://doi.org/10.1111/jmi.12910 ([Journal Article; Research Support, Non-U.S. Gov't])

Sadeghi L, Babadi VY, Tanwir F (2018) Manganese dioxide nanoparticle induces Parkinson like neurobehavioral abnormalities in rats. Bratisl Lek Listy 119(6):379-384. https://doi.org/10. 4149/BLL_2018_070 ([Journal Article])

Sansanaphongpricha K, Sonthithai P, Kaewkong P, Thavornyutikarn B, Bamrungsap S, Kosorn W, Thinbanmai T, Saengkrit N (2020) Hyaluronic acid-coated gold nanorods enhancing BMP-2 peptide delivery for chondrogenesis. Nanotechnology 31(43):435101. https://doi.org/10.1088/1361-6528/aba46d ([Journal Article])

Sarkar A, Carvalho E, D’Souza AA, Banerjee R (2019) Liposomeencapsulated fish oil protein-tagged gold nanoparticles for intra-articular therapy in osteoarthritis. Nanomedicine (Lond) 14(7):871-887. https://doi.org/10.2217/nnm-2018-0221 ([Journal Article; Research Support, Non-U.S. Gov't])

Scanzello CR, Goldring SR (2012) The role of synovitis in osteoarthritis pathogenesis. Bone 51(2):249-257. https://doi.org/10.1016/j. bone.2012.02.012 ([Journal Article; Research Support, N.I.H., Extramural; Review])

Shmagel A, Onizuka N, Langsetmo L, Vo T, Foley R, Ensrud K, Valen $P$ (2018) Low magnesium intake is associated with increased knee pain in subjects with radiographic knee osteoarthritis: data from the Osteoarthritis Initiative. Osteoarthritis Cartilage 26(5):651658. https://doi.org/10.1016/j.joca.2018.02.002 ([Journal Article; Research Support, Non-U.S. Gov't; Research Support, U.S. Gov't, Non-P.H.S.])

Singh N, Savanur MA, Srivastava S, D’Silva P, Mugesh G (2019) A manganese oxide nanozyme prevents the oxidative damage of biomolecules without affecting the endogenous antioxidant system. Nanoscale 11(9):3855-3863. https://doi.org/10.1039/c8nr09397k ([Journal Article])

Singh P, Kim YJ, Zhang D, Yang DC (2016) Biological synthesis of nanoparticles from plants and microorganisms. Trends Biotechnol 34(7):588-599. https://doi.org/10.1016/j.tibtech.2016.02.006 ([Journal Article; Research Support, Non-U.S. Gov't; Review])

Singh P, Pandit S, Mokkapati V, Garg A, Ravikumar V, Mijakovic I (2018) Gold nanoparticles in diagnostics and therapeutics for human cancer. Int J Mol Sci 19(7):1979. https://doi.org/10.3390/ ijms19071979 ([Journal Article; Review]) 
Sun H, Liu Y, Bai X, Zhou X, Zhou H, Liu S, Yan B (2018) Induction of oxidative stress and sensitization of cancer cells to paclitaxel by gold nanoparticles with different charge densities and hydrophobicities. J Mater Chem B 6(11):1633-1639. https://doi.org/10. 1039/c7tb03153j ([Journal Article])

Suryavanshi A, Khanna K, Sindhu KR, Bellare J, Srivastava R (2017) Magnesium oxide nanoparticle-loaded polycaprolactone composite electrospun fiber scaffolds for bone-soft tissue engineering applications: in-vitro and in-vivo evaluation. Biomed Mater 12(5):55011. https://doi.org/10.1088/1748-605X/aa792b ([Journal Article])

Tootoonchi MH, Hashempour M, Blackwelder PL, Fraker CA (2017) Manganese oxide particles as cytoprotective, oxygen generating agents. Acta Biomater 59:327-337. https://doi.org/10.1016/j.actbio.2017.07.006 ([Journal Article; Research Support, Non-U.S. Gov't])

Torzilli PA, Arduino JM, Gregory JD, Bansal M (1997) Effect of proteoglycan removal on solute mobility in articular cartilage. $\mathbf{J}$ Biomech 30(9):895-902. https://doi.org/10.1016/s0021-9290(97) 00059-6 ([Journal Article; Research Support, U.S. Gov't, P.H.S.])

Tuschl K, Mills PB, Clayton PT (2013) Manganese and the brain. Int Rev Neurobiol 110:277-312. https://doi.org/10.1016/B978-0-12410502-7.00013-2 ([Journal Article; Review])

Vazquez KJ, Andreae JT, Henak CR (2019) Cartilage-on-cartilage cyclic loading induces mechanical and structural damage. J Mech Behav Biomed Mater 98:262-267. https://doi.org/10.1016/j. jmbbm.2019.06.023 ([Journal Article; Research Support, N.I.H., Extramural; Research Support, Non-U.S. Gov't])

Veronese N, La Tegola L, Caruso MG, Maggi S, Guglielmi G (2019) The association between dietary magnesium intake and magnetic resonance parameters for knee osteoarthritis. Nutrients 11(6):1387. https://doi.org/10.3390/nu11061387 ([Evaluation Study; Journal Article])

Wang D, Lin Z, Wang T, Yao Z, Qin M, Zheng S, Lu W (2016) Where does the toxicity of metal oxide nanoparticles come from: the nanoparticles, the ions, or a combination of both? J Hazard Mater 308:328-334. https://doi.org/10.1016/j.jhazmat.2016.01.066 ([Journal Article; Research Support, Non-U.S. Gov't])

Wang Z, Yang J, Yang Y, Pu X, Zhao J, Zhang N (2020) Targeted and combined TPCA-1-gold nanocage therapy for in vivo treatment of inflammatory arthritis. AAPS PharmSciTech 21(8):298. https:// doi.org/10.1208/s12249-020-01856-0 ([Journal Article])

Watanabe K, Shibuya S, Ozawa Y, Nojiri H, Izuo N, Yokote K, Shimizu T (2014) Superoxide dismutase 1 loss disturbs intracellular redox signaling, resulting in global age-related pathological changes. Biomed Res Int 2014:140165. https://doi.org/10.1155/ 2014/140165 ([Journal Article; Research Support, Non-U.S. Gov't; Review])

Wathiong B, Deville S, Jacobs A, Smisdom N, Gervois P, Lambrichts I, Ameloot M, Hooyberghs J, Nelissen I (2019) Role of nanoparticle size and sialic acids in the distinct time-evolution profiles of nanoparticle uptake in hematopoietic progenitor cells and monocytes. J Nanobiotechnology 17(1):62. https://doi.org/10.1186/s12951019-0495-x ([Journal Article])

Wu M, Guo H, Liu L, Liu Y, Xie L (2019) Size-dependent cellular uptake and localization profiles of silver nanoparticles. Int J
Nanomedicine 14:4247-4259. https://doi.org/10.2147/IJN.S2011 07 ([Journal Article])

Yao H, Xu JK, Zheng NY, Wang JL, Mok SW, Lee YW, Shi L, Wang JY, Yue J, Yung SH, Hu PJ, Ruan YC, Zhang YF, Ho KW, Qin L (2019) Intra-articular injection of magnesium chloride attenuates osteoarthritis progression in rats. Osteoarthritis Cartilage 27(12):1811-1821. https://doi.org/10.1016/j.joca.2019.08.007 ([Journal Article; Research Support, Non-U.S. Gov't])

Yue J, Jin S, Gu S, Sun R, Liang Q (2019) High concentration magnesium inhibits extracellular matrix calcification and protects articular cartilage via Erk/autophagy pathway. J Cell Physiol 234(12):23190-23201. https://doi.org/10.1002/jcp.28885 ([Journal Article; Research Support, Non-U.S. Gov't])

Zelzer E, Mamluk R, Ferrara N, Johnson RS, Schipani E, Olsen BR (2004) VEGFA is necessary for chondrocyte survival during bone development. Development 131(9):2161-2171. https://doi.org/10. 1242/dev.01053 ([Journal Article; Research Support, U.S. Gov’t, P.H.S.])

Zeng C, Wei J, Li H, Yang T, Zhang FJ, Pan D, Xiao YB, Yang TB, Lei GH (2015) Relationship between serum magnesium concentration and radiographic knee osteoarthritis. J Rheumatol 42(7):12311236. https://doi.org/10.3899/jrheum.141414 ([Journal Article; Research Support, Non-U.S. Gov't])

Zhang D, Liu D, Zhang J, Fong C, Yang M (2014) Gold nanoparticles stimulate differentiation and mineralization of primary osteoblasts through the ERK/MAPK signaling pathway. Mater Sci Eng C Mater Biol Appl 42:70-77. https://doi.org/10.1016/j.msec.2014. 04.042 ([Journal Article; Research Support, Non-U.S. Gov't])

Zhang L, Su H, Wang H, Li Q, Li X, Zhou C, Xu J, Chai Y, Liang X, Xiong L, Zhang C (2019) Tumor chemo-radiotherapy with rodshaped and spherical gold nano probes: shape and active targeting both matter. Theranostics 9(7):1893-1908. https://doi.org/10. 7150/thno.30523 ([Journal Article; Research Support, Non-U.S. Gov't])

Zheng Q, Fang Y, Zeng L, Li X, Chen H, Song H, Huang J, Shi S (2019) Cytocompatible cerium oxide-mediated antioxidative stress in inhibiting ocular inflammation-associated corneal neovascularization. J Mater Chem B 7(43):6759-6769. https://doi. org/10.1039/c9tb01066a ([Journal Article; Research Support, Non-U.S. Gov't])

Zhou HF, Chan HW, Wickline SA, Lanza GM, Pham CT (2009) Alphavbeta3-targeted nanotherapy suppresses inflammatory arthritis in mice. FASEB J 23(9):2978-2985. https://doi.org/10. 1096/fi.09-129874 ([Journal Article; Research Support, N.I.H., Extramural])

Zhou J, Liu C, Sun Y, Francis M, Ryu MS, Grider A, Ye K (2021) Genetically predicted circulating levels of copper and zinc are associated with osteoarthritis but not with rheumatoid arthritis. Osteoarthritis Cartilage. https://doi.org/10.1016/j.joca.2021.02. 564 ([Journal Article])

Publisher's note Springer Nature remains neutral with regard to jurisdictional claims in published maps and institutional affiliations. 